Check for updates

Cite this: RSC Adv., 2018, 8, 1182

Received 22nd September 2017 Accepted 20th December 2017

DOI: 10.1039/c7ra10533a

rsc.li/rsc-advances

\section{LC-ESI-MS/MS reveals the formation of reactive intermediates in brigatinib metabolism: elucidation of bioactivation pathways}

\begin{abstract}
Adnan A. Kadi, ${ }^{a}$ Mohamed W. Attwa (D) *a and Hany W. Darwish ${ }^{\text {ab }}$
Brigatinib (BGB) is a newly approved anaplastic lymphoma kinase (ALK) inhibitor. On April 28, 2017, BGB was approved by the U.S. FDA for the treatment of metastatic anaplastic lymphoma kinase-positive non-small cell lung cancer. The toxicity profile of BGB includes nausea, fatigue, diarrhea, elevated lipase, dyspnoea, hypertension, hypoxia, pneumonia, elevated amylase, pulmonary embolism, elevated ALT, hyponatraemia and hypophosphatemia. Using LC-MS/MS, we investigated the in vitro phase I metabolism of for BGB in rat liver microsomes (RLMs). In the in vitro metabolism of $B G B$, iminium reactive intermediates were trapped by potassium cyanide forming a stable complex that can be characterized by LC-MS/MS. Four $\mathrm{BGB}$ in vitro phase I metabolites were identified. In vitro phase I metabolic pathways were $N$-dealkylation, $\alpha$ hydroxylation and $\alpha$ oxidation. Additionally, three iminium reactive metabolites were found and the bioactivation mechanisms were proposed. A piperidine ring was found to be responsible for $B G B$ bioactivation. The presence of these three reactive metabolites may be the main reason for $B G B$ side effects. A literature review showed no previous article reported the in vitro phase I metabolism study of $\mathrm{BGB}$ or structural identification of the formed reactive metabolites.
\end{abstract}

\section{Introduction}

Lung cancer is considered the most common reason of death from cancer worldwide. It is considered to be responsible for almost $20 \%$ of total cancer deaths (1.59 million deaths) in 2012. ${ }^{1}$ Non-small cell lung cancers (NSCLCs) represented about $90 \%$ of lung cancers, which include a number of subtypes driven by various activated oncogenes. ${ }^{2,3}$ New advances in molecular profiling technologies have considerably enhanced the development of personalised therapies based on individual genetic or protein profiles. ${ }^{4,5}$ Targeted personalised therapies achieved great success in treating NSCLC patients. ${ }^{6-8}$ ALK is an insulin receptor tyrosine kinase family (RTK) member. ${ }^{9}$ ALK inhibitors are anti cancer drugs that act on tumours with variations of ALK such as an EML4-ALK translocation. ${ }^{10}$ EML4-ALK translocations represented about $4-7 \%$ of non-small cell lung carcinomas (NSCLC). ${ }^{11}$

BGB (ALUNBRIG tablets) is an orally available ALK inhibitor that demonstrated ability to overcome crizotinib resistance mutations. ${ }^{12,13}$ On April 28, 2017, BGB was approved by the US FDA for the treatment of patients with metastatic ALK-positive NSCLC that have progressed on or are intolerant to crizotinib.

${ }^{a}$ Department of Pharmaceutical Chemistry, College of Pharmacy, King Saud University, P. O. Box 2457, Riyadh, 11451, Kingdom of Saudi Arabia. E-mail: mzeidan@ksu.edu. sa; Fax: +966114676 220; Tel: +966 114670237

${ }^{b}$ Analytical Chemistry Department, Faculty of Pharmacy, Cairo University, Kasr El-Aini St., Cairo 11562, Egypt
Metabolism is considered a detoxification process that responsible for increasing of the hydrophilicity of xenobiotics and endogenous compounds to be easily excreted from the body. Metabolites are usually less toxic if compared to parent molecules, but in rare cases bioactivation occurred forming reactive intermediates that can covalently modify proteins initiating drug-organ toxicities steps. ${ }^{\mathbf{1 4 - 1 8}}$ Reactive intermediates are generated in most cases from phase I metabolism and are considered crucial in drug induced toxicity. Reactive metabolites such as iminium ion are unstable, formed in small amounts, and react rapidly with nucleophiles within matrix such as proteins and can, therefore, not found in regular metabolism studies. Hard electrophiles (such as iminium ions) react with hard nucleophiles, such as lysine residues in proteins and basic groups in DNA. ${ }^{19}$ Methods used to trap reactive<smiles>COc1cc(N2CCC(N3CCN(C)CC3)CC2)ccc1Nc1ncc(Cl)/c(=N\c2ccccc2P(C)(C)=O)[nH]1</smiles>

Fig. 1 Chemical structure of brigatinib. 
Table 1 LC-MS/MS method parameters

Liquid chromatographic parameters

HPLC
Gradient binary mobile phase

Agilent eclipse plus $\mathrm{C}_{18}$ Column

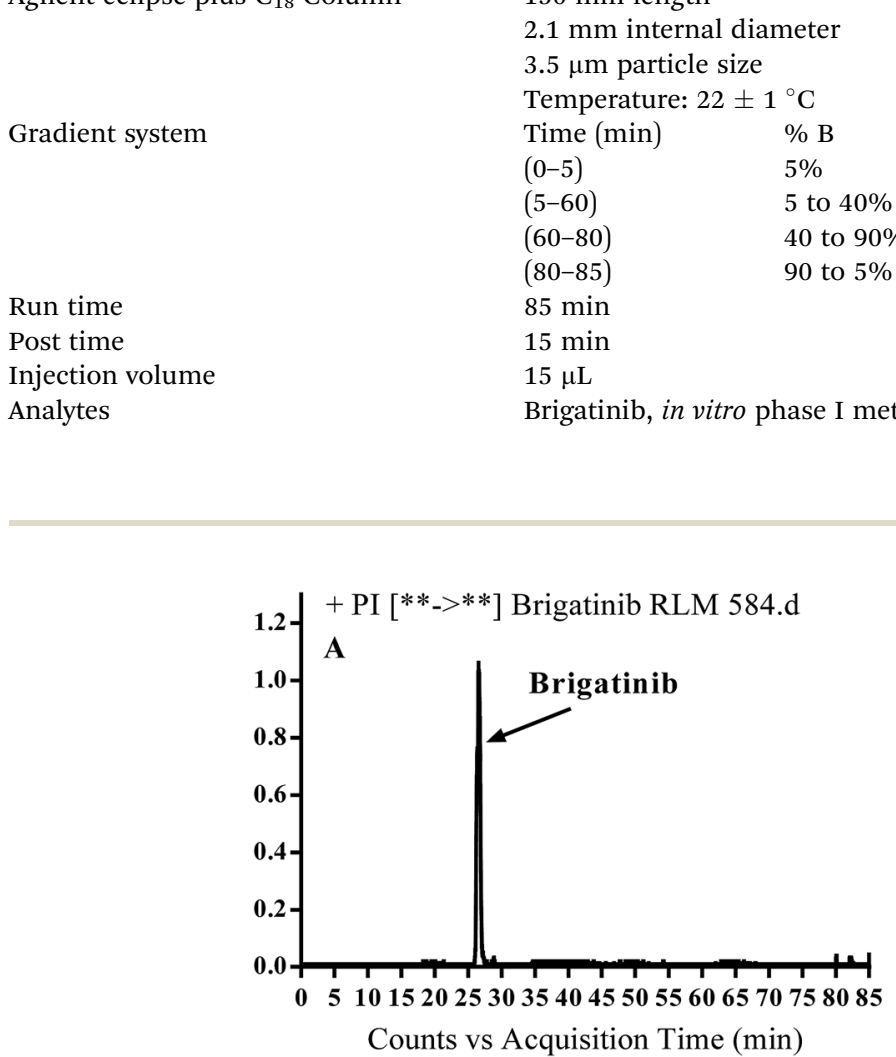

Agilent 1200

A: $0.1 \%$ formic acid in $\mathrm{H}_{2} \mathrm{O}$

B: ACN

Flow rate: $0.3 \mathrm{~mL} \mathrm{~min}^{-1}$

$150 \mathrm{~mm}$ length

$2.1 \mathrm{~mm}$ internal diameter

$3.5 \mu \mathrm{m}$ particle size

Temperature: $22 \pm 1{ }^{\circ} \mathrm{C}$

Time (min) $\quad \% \mathrm{~B}$

$(5-60)$

(60-80)

$85 \mathrm{~min}$

$15 \mathrm{~min}$

Brigatinib, in vitro phase I metabolites and cyano adducts
Mass spectrometric parameters
Mass spectrometer

Ionization source

Mass parameters
Agilent 6410 QQQ

Drying gas: $\mathrm{N}_{2}$ gas

Flow rate $\left(12 \mathrm{~L} \mathrm{~min}^{-1}\right)$

Pressure (60 psi)

Desolvation temperature: $350{ }^{\circ} \mathrm{C}$

Capillary voltage: $4000 \mathrm{~V}$

High purity $\mathrm{N}_{2}$

Mode: positive product ion (PI)

Fragmentor voltage: $145 \mathrm{~V}$

Capillary voltage: $4000 \mathrm{~V}$

Collision energy: $30 \mathrm{eV}$

Fig. 2 PI chromatogram of MIP at $m / z 584$ showing BGB peak at $26.6 \mathrm{~min}(\mathrm{~A})$, PI mass spectrum of BGB (B).

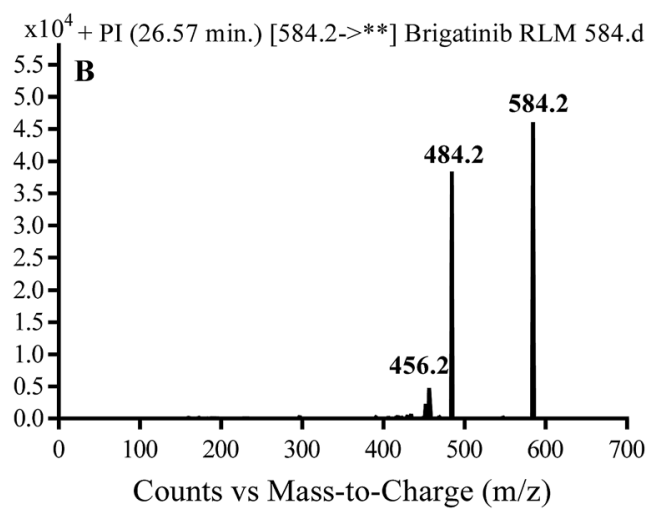<smiles>COc1cc(N2CCC(N3CCN(C)CC3)CC2)ccc1Nc1ncc(Cl)c(=Nc2ccccc2P(C)(C)=O)[nH]1</smiles>

Scheme 1 Fragmentation pattern of BGB. 
Table 2 Phase I metabolites of BGB

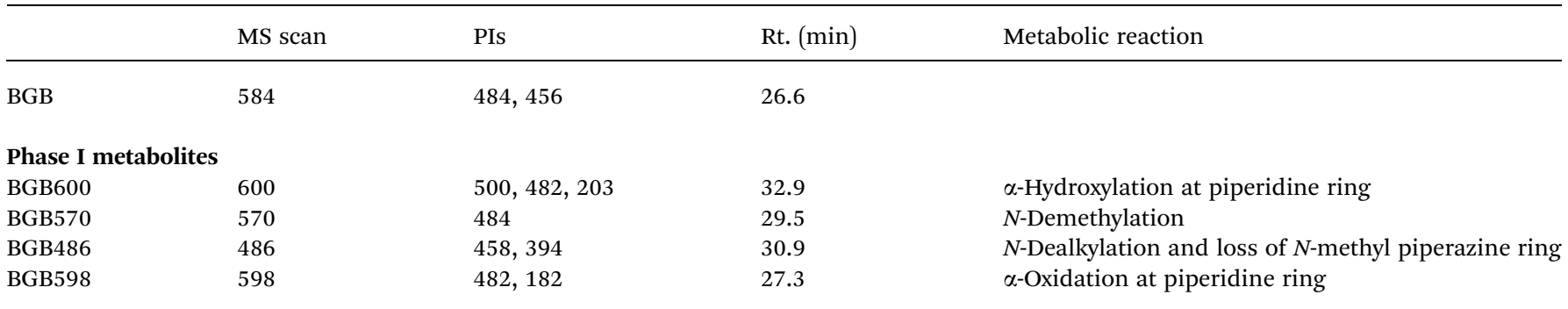
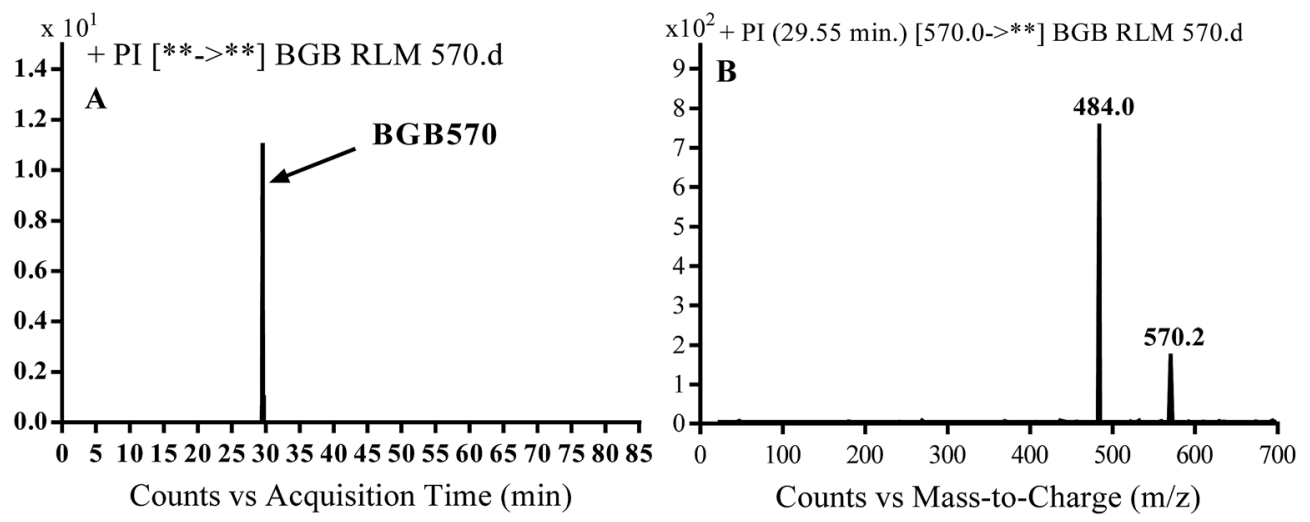

Fig. 3 PI chromatogram of MIP at $\mathrm{m} / z 570$ showing BGB570 peak at $29.5 \mathrm{~min}$ (A), PI spectrum of BGB570 (B).<smiles>COc1cc(N2CCC(C3CCNCC3)CC2)ccc1Nc1ncc(Cl)/c(=N/c2ccccc2P(C)(C)=O)[nH]1</smiles><smiles>COc1cc(N2CC=CCC2)ccc1Nc1ncc(Cl)/c(=N/c2ccccc2P(C)(C)=O)[nH]1</smiles>

$\mathrm{m} / \mathrm{z}: 484$

Scheme 2 Fragmentation pattern of BGB570.

intermediates are well established and were used for screening of these intermediates in early drug discovery ${ }^{20}$ Direct detection and characterization of reactive intermediates are not possible due to their unstable and transient nature, so trapping agent was used forming adducts that are stable and can be analyzed by tandem mass spectrometry. ${ }^{21,22}$

The low concentration (nM) of metabolites and the complex nature of biological matrices made metabolite characterization an analytical challenge. Liquid chromatography mass spectrometry (LC-MS) has become the analytical tool of choice for the detection and identification of metabolite as it is characterized by high sensitivity, selectivity and its ability to separate, detect, and identify many metabolites in the presence of complex matrix. ${ }^{23}$

BGB chemical structure contains $N$-methyl piperazine and piperidine groups which are cyclic tertiary amine groups (Fig. 1) that undergo bioactivation forming iminium ion intermediate ${ }^{24-26}$ that are hard electrophiles and can be trapped efficiently by KCN. ${ }^{14,24,25,27}$ The formed adducts can be separated, detected and characterized using LC-MS/ MS. ${ }^{21,22,24,28,29}$

In our work, we are profiling unreported in vitro phase I metabolites of brigatinib and we are trying to give insight about the reasons which may be responsible for the observed side effects of BGB. The toxicity profile of BGB includes nausea, fatigue, diarrhea, elevated lipase, dyspnoea, hypertension, hypoxia, pneumonia, elevated amylase, fatigue, pulmonary embolism, elevated ALT, hyponatraemia and hypophosphatemia. ${ }^{30}$ We are illuminating the way towards further developing ALK inhibitors with lower side effects. $N$-Demethylated in vitro phase I metabolite of BGB was reported, ${ }^{31}$ while other metabolites or adducts were not reported. Although BGB contains $N$-methyl piperazine group, we found that it had no role in bioactivation of BGB that is differ than other TKIs. ${ }^{27}$ 

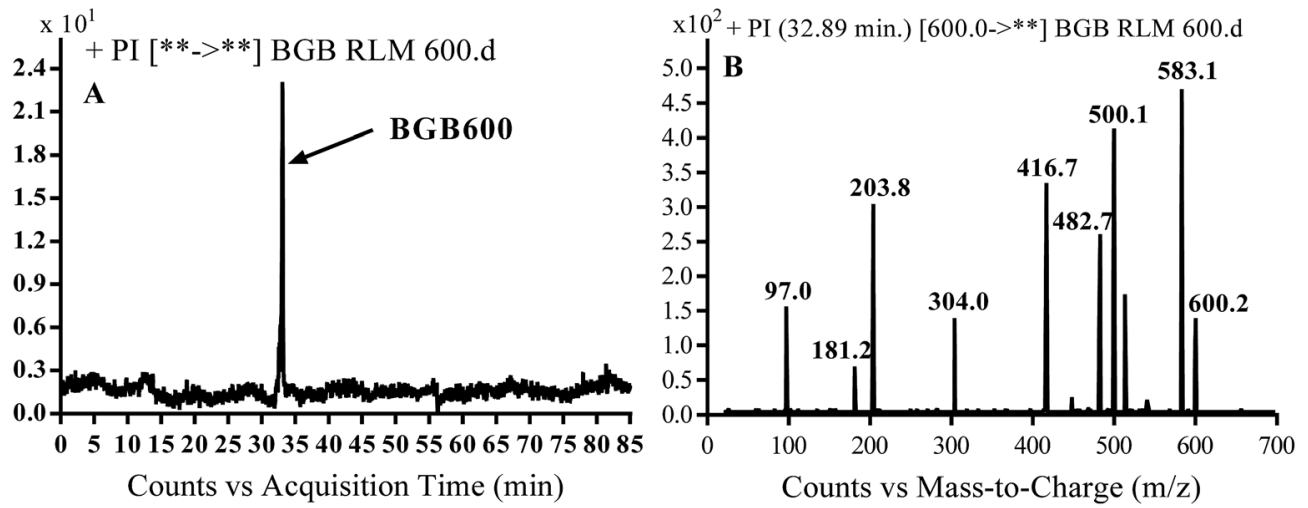

Fig. $4 \mathrm{PI}$ chromatogram of MIP at $\mathrm{m} / \mathrm{z} 600$ showing BGB600 peak at $32.9 \mathrm{~min}$ (A), PI spectrum of BGB600 (B).

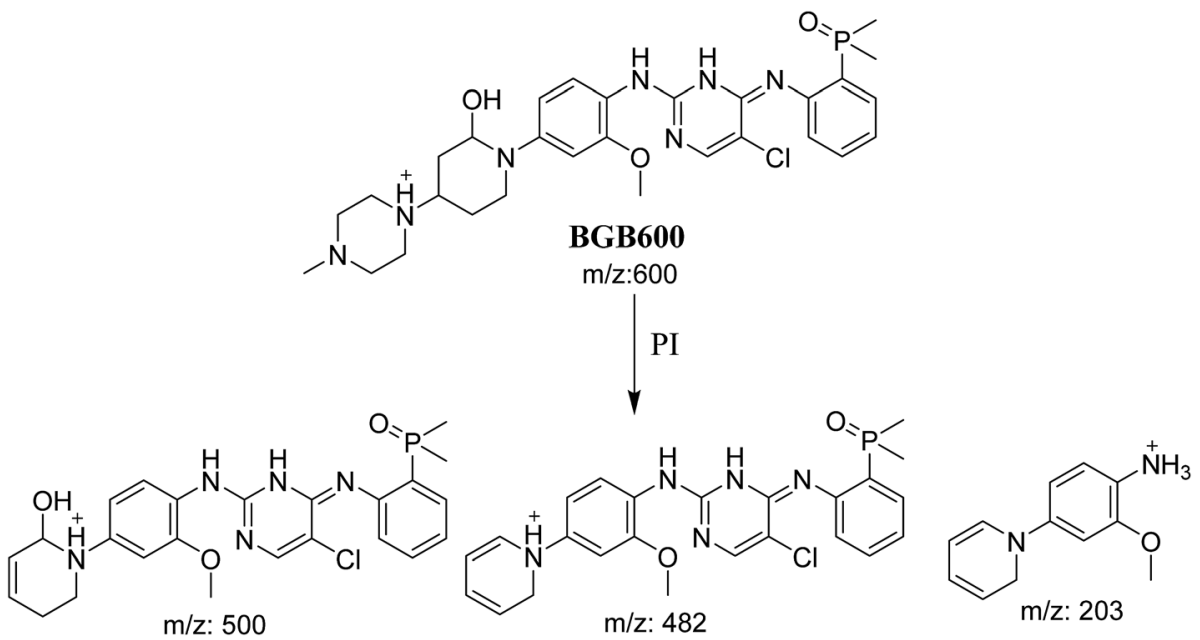

Scheme 3 Fragmentation pattern of BGB600.
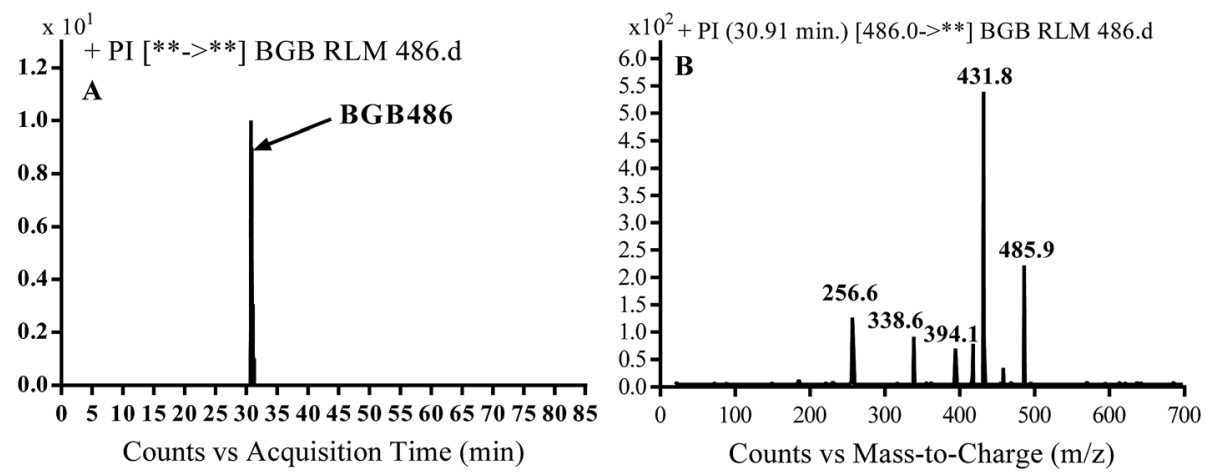

Fig. $5 \mathrm{Pl}$ chromatogram of MIP at $m / z 486$ showing BGB486 peak at 30.9 min (A), PI mass spectrum of BGB486 (B).

Piperidine group of BGB was found to be responsible for BGB bioactivation.

\section{Chemicals and methods}

\subsection{Chemicals}

BGB was procured from Med Chem. Express (Princeton, NJ, USA). HPLC-grade Acetonitrile (ACN), potassium cyanide (KCN) and formic acid were purchased from Sigma-Aldrich (West Chester, PA, USA). Purified water was obtained from in-house Milli-Q plus purification system. RLMs were prepared inhouse using Sprague Dawley rats following a previously published method. ${ }^{32}$ Sprague Dawley rats were obtained from Animal Care Center, College of Pharmacy, King Saud University. Animals' were maintained following the guidelines of Animal Care Center, College of Pharmacy, King Saud University and 
<smiles>CC(C)(C)CCCCOC(C)(C)C</smiles>

\section{BGB486}

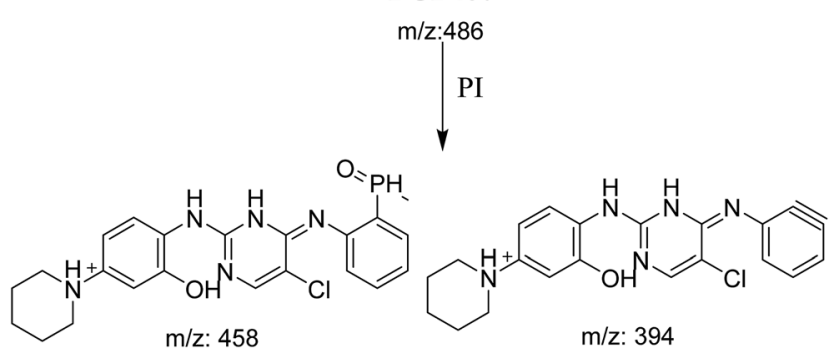

Scheme 4 Fragmentation pattern of BGB486.

approved by Local Animal Care and Use Committee of King Saud University.

\subsection{LC-MS/MS chromatographic parameters}

LC-MS/MS parameters are summarized in Table 1. Slow gradient binary mobile phase is used to separate closely related metabolites. Positive mode was used for BGB detection as BGB chemical structure contains many basic nitrogen that can be easily protonated and this matched with the literature. ${ }^{33}$ Product ions (PIs) of BGB, in vitro phase I metabolites and cyano adducts in the collision cell. LC-MS/MS system and data acquisition were controlled by Mass Hunter software.
Table 3 Cyano adducts of BGB

\begin{tabular}{|c|c|c|c|c|}
\hline & $\begin{array}{l}\text { MS } \\
\text { scan }\end{array}$ & $\begin{array}{l}\text { Most abundant } \\
\text { fragment ions }\end{array}$ & Rt. (min) & Metabolic reaction \\
\hline BGB609 & 609 & 482 & 31.4 & Cyano addition \\
\hline BGB623 & 623 & 596,482 & 42.9 & $\begin{array}{l}\text { Cyano addition and } \\
\text { oxidation at } N \text {-methyl } \\
\text { piperazine ring }\end{array}$ \\
\hline BGB527 & 527 & 482,416 & 43.9 & $\begin{array}{l}\text { Cyano addition, } \\
\alpha \text { hydroxylation at } \\
\text { piperidine ring and } \\
\text { loss of } N \text {-methyl } \\
\text { piperazine group }\end{array}$ \\
\hline
\end{tabular}

\subsection{RLMs incubations of BGB}

Ten $\mu \mathrm{M}$ BGB was incubated with $40 \mu \mathrm{L}$ RLMs $\left(1.0 \mathrm{mg} \mathrm{mL}^{-1}\right.$ ), $\mathrm{NADPH}(1.0 \mathrm{mM})$ and $\mathrm{Na} / \mathrm{K}$ phosphate buffer $(50 \mathrm{mM}$ containing $3.3 \mathrm{mM} \mathrm{MgCl}_{2}, \mathrm{pH}$ 7.4). Metabolic mixtures were kept for 2 hours in a shaking water bath at $37{ }^{\circ} \mathrm{C}$ and then the reactions were stopped by adding $2 \mathrm{~mL}$ of ice-cold ACN for protein precipitation. Centrifugation was done at $14000 \mathrm{rpm}, 10 \mathrm{~min}$ and $4{ }^{\circ} \mathrm{C}$ to devoid of precipitated proteins. The supernatants were removed, evaporated and reconstituted in the mobile phase at the start of the gradient system (5\% ACN/95\% (0.1\% formic acid in water)). The same experiment of RLMs incubation was repeated with $1.0 \mathrm{mM} \mathrm{KCN}$ to capture bioactive metabolites. Incubations were performed in triplicate to confirm the obtained results.
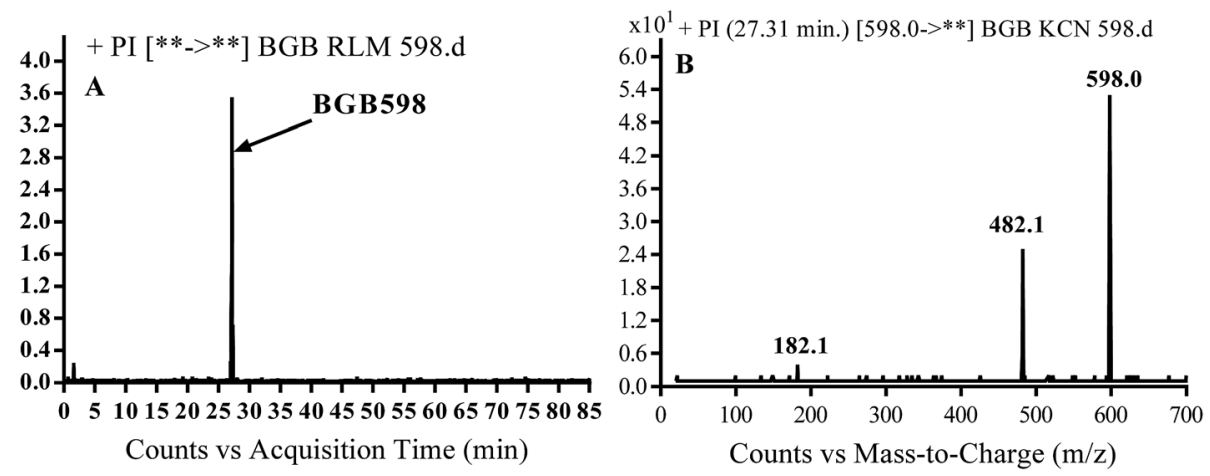

Fig. $6 \mathrm{PI}$ chromatogram of MIP at $\mathrm{m} / z 486$ showing BGB598 peak at 27.3 min (A), PI mass spectrum of BGB598 (B).<smiles>COc1cc(N2CCC(N3CCN(C)CC3)CC2=O)ccc1Nc1ncc(Cl)/c(=N\c2ccccc2P(C)(C)=O)[nH]1</smiles>

Scheme 5 Fragmentation pattern of BGB598. 

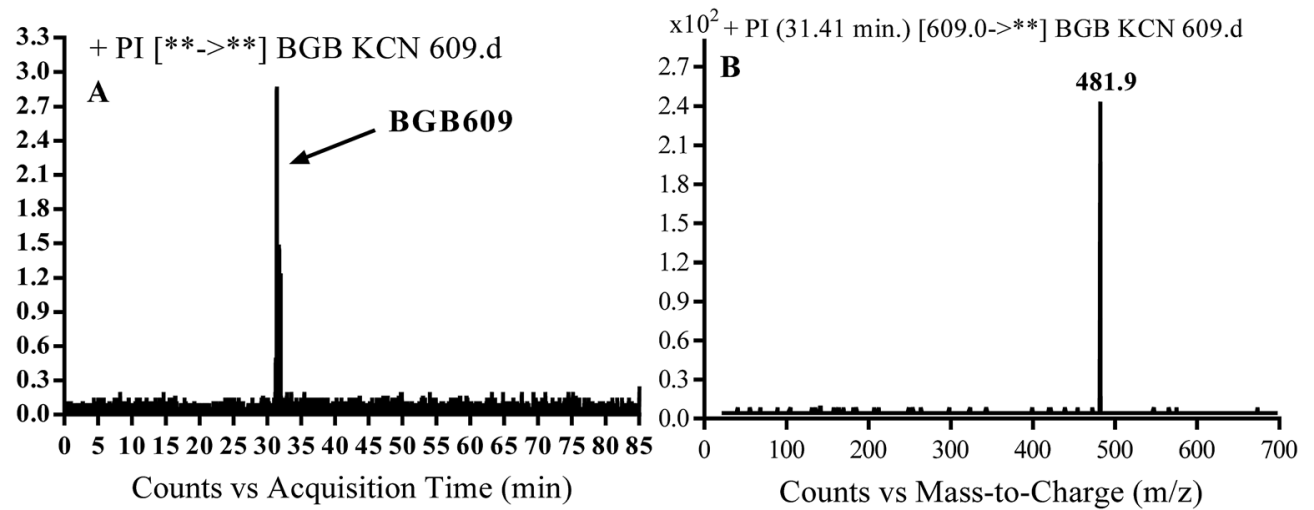

Fig. $7 \mathrm{PI}$ chromatogram of MIP at m/z 609 showing BGB609 peak at 31.4 min (A), PI mass spectrum of BGB609 (B).<smiles>COc1cc(N2CCC([NH+]3CCN(C)CC3)CC2C#N)ccc1Nc1ncc(Cl)/c(=N\c2ccccc2P(C)(C)=O)[nH]1</smiles>

Scheme 6 Fragmentation pattern of BGB609.
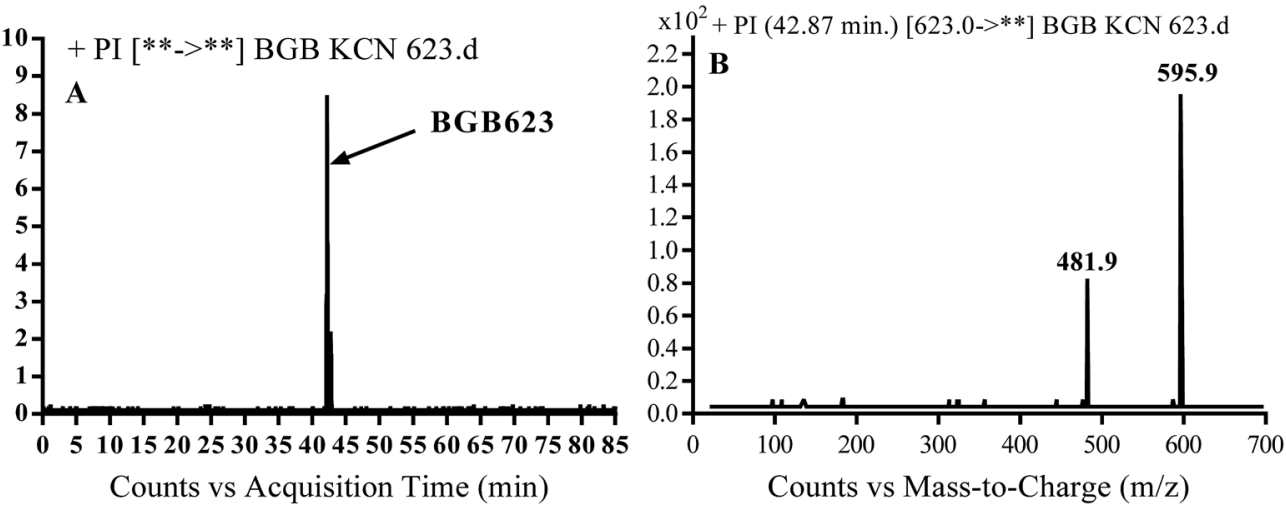

Fig. $8 \mathrm{PI}$ chromatogram of MIP at $m / z 623$ showing BGB623 peak at 42.8 min (A), PI mass spectrum of BGB623 (B).

\subsection{Identification of phase $I$ and reactive metabolites of BGB}

Full MS scan and PI modes were used for identification and characterization of $\mathrm{BGB}$, its in vitro phase I metabolites and cyano adducts. In order to get as much qualitative information as we can, we used PI mode and we used all fragments. PI mode gave more qualitative information comparing to multiple reaction monitoring mode which is mainly used for quantification as stated in the LC-MS/MS method for quantification of BGB. $^{33}$ Extracted ion chromatogram (EIC) of $\mathrm{m} / \mathrm{z}$ of the supposed BGB related metabolites was used to locate and characterize in vitro phase I and reactive metabolites in the total ion chromatogram of the metabolic mixture extract. Comparison of the EICs of the metabolic extract was done with control incubations (that does not contain either BGB or RLMs).

\section{Results and discussion}

\subsection{PI study of BGB}

BGB molecular ion peak (MIP) appears as $[\mathrm{M}+\mathrm{H}]^{+}(\mathrm{m} / z 584)$ at $26.6 \mathrm{~min}$ in TIC chromatogram (Fig. 2A). Fragmentation of parent ion at $m / z 584$ gave two PI at $m / z 484$ and at $m / z 456$ (Fig. 2B). The PI at $\mathrm{m} / \mathrm{z} 484$ represents the loss of $N$-methyl piperazine group by single bond cleavage (Scheme 1) as reported in the literature. ${ }^{33}$

\subsection{Identification of in vitro phase I BGB metabolites}

Three in vitro phase I metabolic pathways generated four metabolites through: $N$-dealkylation, $\alpha$ hydroxylation and $\alpha$ oxidation (Table 2). Metabolites were not observed in control incubations (that does not contains either BGB or RLMs). 
<smiles>CC(C)COc1cc(N2CCC(N3CCN(C)CC3=O)CC2C#N)ccc1Nc1ncc(Cl)c(=Nc2ccccc2P(C)(C)=O)[nH]1</smiles><smiles>COc1cc(N2C=CC(N3CCN(C)CC3=O)CC2)ccc1Nc1ncc(Cl)/c(=N/c2ccccc2P(C)(=O)C[Y](C)(C)C)[nH]1</smiles>

Scheme 7 Fragmentation pattern of BGB623.
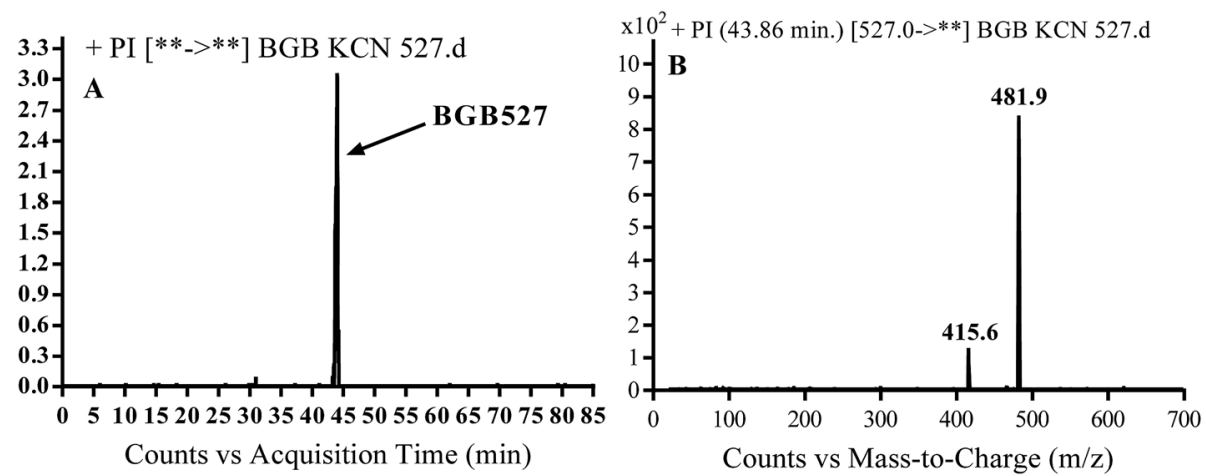

Fig. $9 \mathrm{PI}$ chromatogram of MIP at $\mathrm{m} / \mathrm{z} 527$ showing BGB527 peak at $43.9 \mathrm{~min}$ (A), PI mass spectrum of BGB527 (B).

3.2.1. Identification of BGB570 phase I metabolite of BGB. BGB570 MIP appears as $[\mathrm{M}+\mathrm{H}]^{+}(\mathrm{m} / z$ 570) at $29.5 \mathrm{~min}$ in PI chromatogram (Fig. 3A). Fragmentation of BGB570 gave one PI at $m / z 484$ (Fig. 3B) which represents loss of piperazine ring. PI at $m / z 484$ proposed that metabolic change occurred in the piperazine ring. The PI at $m / z 484$ revealed that $N$-demethylation of $N$-methyl piperazine ring of BGB570 (Scheme 2).

3.2.2. Identification of BGB600 phase I metabolite of BGB. BGB600 MIP appears as $[\mathrm{M}+\mathrm{H}]^{+}(\mathrm{m} / z$ 600) at $32.4 \mathrm{~min}$ in PI chromatogram (Fig. 4A). Fragmentation of BGB600 at $\mathrm{m} / z 600$ gave PI at $m / z 500, m / z 482$ and $m / z 203$ (Fig. 4B). PI at $m / z 500$ proposed that metabolic change was occurred in the piperazine ring. Hydroxylation was proposed to occur in the $\alpha$ position of piperidine nitrogen atom (Scheme 3).

3.2.3. Identification of BGB486 phase I metabolite of BGB. BGB486 MIP appears as $[\mathrm{M}+\mathrm{H}]^{+}(\mathrm{m} / \mathrm{z} 486)$ at $30.9 \mathrm{~min}$ in PI chromatogram (Fig. 5A). Fragmentation of parent ion at $\mathrm{m} / \mathrm{z} 486$ gave PI at $m / z 458$ and $m / z 394$ (Fig. 5B). PI at 458 proposed that $N$-dealkylation and loss of $N$-methyl piperazine ring (Scheme 4).

3.2.4. Identification of BGB598 phase I metabolite of BGB. BGB589 MIP appears as $[\mathrm{M}+\mathrm{H}]^{+}(\mathrm{m} / z$ 598) at $27.3 \mathrm{~min}$ in PI chromatogram (Fig. 6B). Fragmentation of parent ion at $m / z 598$ gave PI at $m / z 482$ and $m / z 182$ (Fig. 6B). PI at $m / z 482$ proposed the $\alpha$ oxidation of piperidine group that matched with the other PI at $m / z 182$ (Scheme 5).

\subsection{Reactive metabolites}

Three cyano adducts were detected in the case of incubation of BGB with RLMs in the presence of $1.0 \mathrm{mM}$ KCN (Table 3).

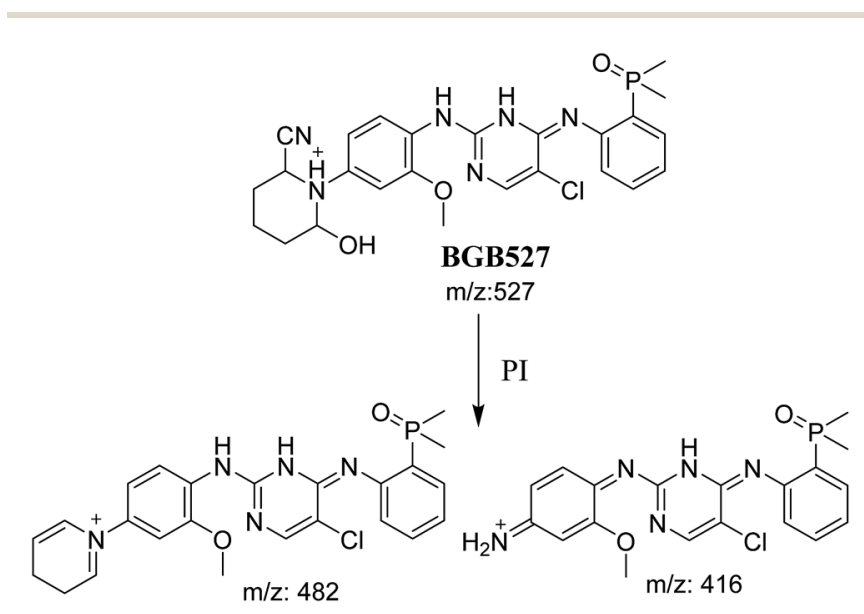

Scheme 8 Fragmentation pattern of BGB527. 


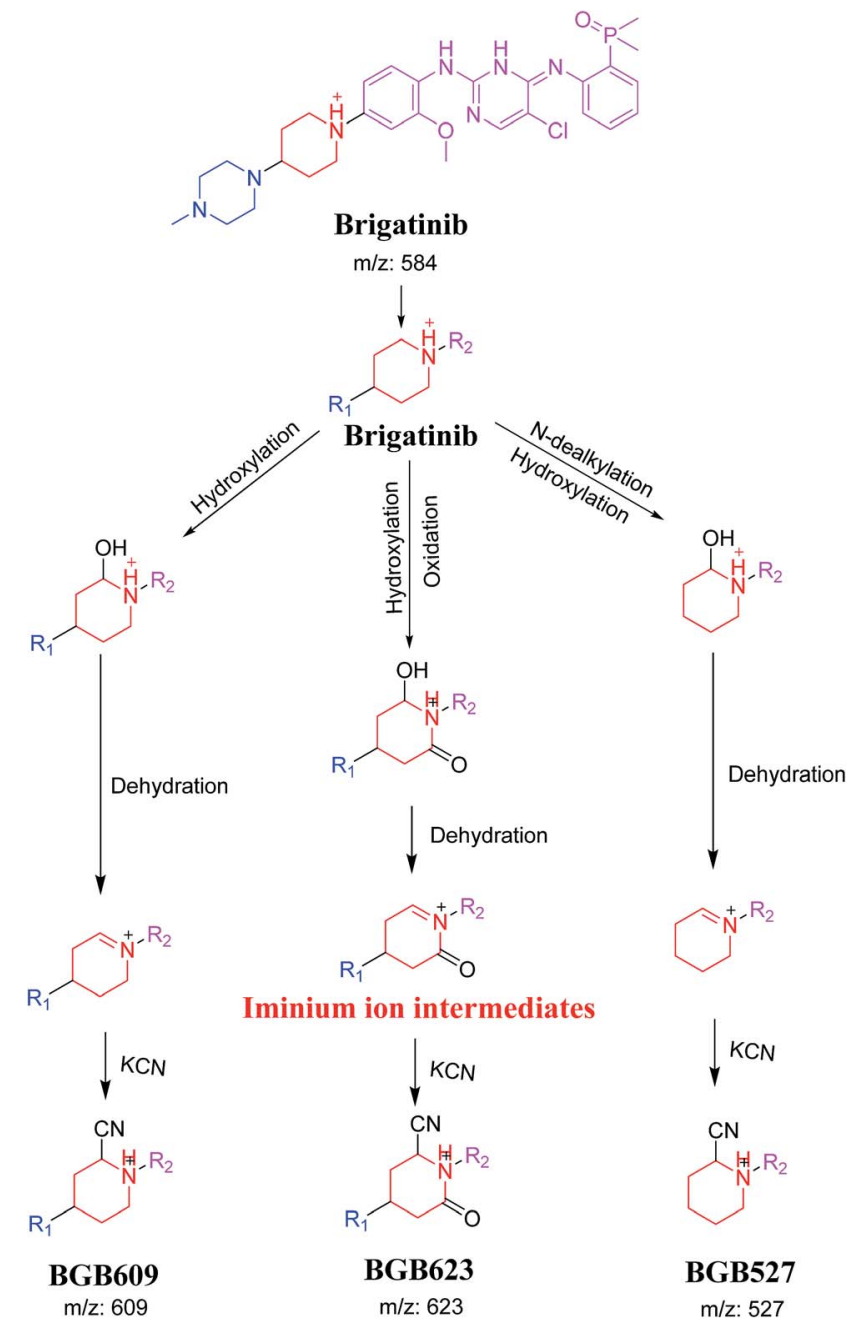

Scheme 9 Proposed mechanism of bioactivation of BGB into reactive intermediates and trapping strategy.

3.3.1. Identification of BGB609 cyano adduct of BGB. BGB609 MIP appears as $[\mathbf{M}+\mathrm{H}]^{+}(\mathrm{m} / z$ 609) at $31.4 \mathrm{~min}$ in PI chromatogram (Fig. 7A). Fragmentation of parent ion at $m / z 609$ gave PI at $m / z 482$ (Fig. 7B). The PI at $m / z 482$ represented an immediate elimination of one molecule of $\mathrm{HCN}$ in addition to loss of $N$-methyl piperazine ring. The PI at $\mathrm{m} / \mathrm{z} 482$ proposed the addition of cyanide ion at the activated $\alpha$ carbon of the nitrogen atom of piperidine ring (Scheme 6).

3.3.2. Identification of BGB623 cyano adduct of BGB. BGB623 MIP appears as $[\mathrm{M}+\mathrm{H}]^{+}(\mathrm{m} / z$ 623 $)$ at $42.8 \mathrm{~min}$ in PI chromatogram (Fig. 8A). Fragmentation of parent ion at $m / z 623$ gave PI at $m / z 596$ and $m / z 482$ (Fig. 8B). The PI at $m / z 596$ represented an immediate loss of a molecule of HCN. The PI at $m / z 482$ proposed the addition of cyanide ion at the activated $\alpha$ carbon of piperidine ring. The metabolic reaction of BGB623 proposed to be $\alpha$ oxidation of $N$-methyl piperazine ring and addition of cyanide ion at $\alpha$ position in piperidine ring (Scheme 7).

3.3.3. Identification of BGB527 cyano adduct of BGB. BGB527 MIP appears as $[\mathbf{M}+\mathbf{H}]^{+}(m / z 527)$ at $43.9 \mathrm{~min}$ in PI chromatogram (Fig. 9A). Fragmentation of parent ion at $m / z 527$ gave PI at $m / z 482$ and $m / z 416$ (Fig. 9B). The PI at $m / z 482$ proposed that the addition of cyanide ion at the activated $\alpha$ carbon of the $\mathrm{N}$ atom of piperidine ring. The metabolic reaction of BGB527 proposed to be $\alpha$ hydroxylation and $\alpha$ addition of cyanide ion at piperidine ring, and loss of $N$-methyl piperazine ring through $N$-dealkylation metabolic reaction (Scheme 8).

\subsection{Mechanism of bioactivation of BGB}

The formation of BGB527, BGB609 and BGB623 cyanide adduct indicated that the formation of iminium intermediates in the piperidine ring. $\alpha$ Hydroxylation of piperidine ring in BGB then dehydration resulted in formation of iminium ions (BGB527 and BGB609) or iminium carbonyl (BGB623) that are not stable but can be trapped by cyanide forming stable adduct (Scheme 9). The mechanism of BGB bioactivation is previously described with other similar cyclic tertiary amine containing drugs. ${ }^{34-36}$

\section{Conclusions}

Four phase I BGB metabolites and three cyano adducts for BGB were detected using LC-MS/MS (Fig. 10). Piperidine ring was found to be responsible of BGB bioactivation. This study illuminates the way for further work about BGB side effects.

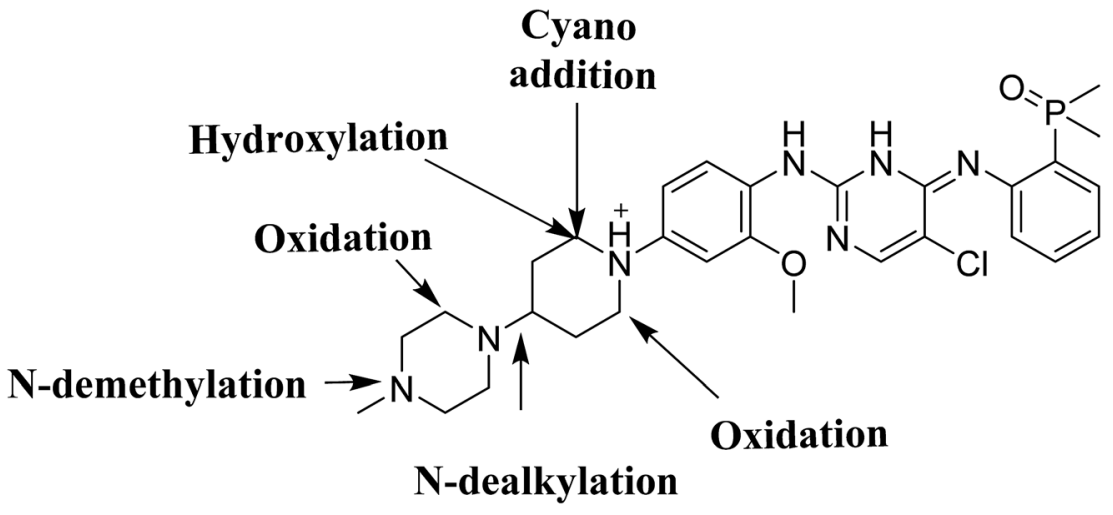

Fig. 10 Chemical structure of BGB showing places of phase I metabolic reaction and bioactivation pathways. 
Isosteric replacements at both $2 \alpha$ carbons of piperidine group can retain activity with reduce side effects by blocking bioactivation pathways.

\section{Conflicts of interest}

The authors declare no conflict of interest.

\section{Acknowledgements}

The authors would like to extend their sincere appreciation to the Deanship of Scientific Research at the King Saud University for funding this work through the Research Group Project No. RGP-1437-033.

\section{References}

1 J. Ferlay, I. Soerjomataram, R. Dikshit, S. Eser, C. Mathers, M. Rebelo, D. M. Parkin, D. Forman and F. Bray, Int. J. Cancer, 2015, 136, E359-E386.

2 D. S. Ettinger, W. Akerley, G. Bepler, M. G. Blum, A. Chang, R. T. Cheney, L. R. Chirieac, T. A. D'Amico, T. L. Demmy and A. K. P. Ganti, J. Natl. Compr. Cancer Network, 2010, 8, 740-801.

3 J. E. Larsen, T. Cascone, D. E. Gerber, J. V. Heymach and J. D. Minna, Cancer J., 2011, 17, 512.

4 M. Arnedos, P. Vielh, J. C. Soria and F. Andre, J. Pathol., 2014, 232, 274-282.

5 F. Meric-Bernstam, C. Farhangfar, J. Mendelsohn and G. B. Mills, J. Clin. Oncol., 2013, 31, 1849-1857.

6 S. Cardarella and B. E. Johnson, Am. J. Respir. Crit. Care Med., 2013, 188, 770-775.

7 T. Li, H.-J. Kung, P. C. Mack and D. R. Gandara, J. Clin. Oncol., 2013, 31, 1039-1049.

8 A. L. Moreira and R. H. Thornton, Clin. Lung Cancer, 2012, 13, 334-339.

9 E. Fisher, H. Charbonneau and N. Tonks, Science, 1991, 253, 401-406.

10 C. Gridelli, S. Peters, A. Sgambato, F. Casaluce, A. A. Adjei and F. Ciardiello, Cancer Treat. Rev., 2014, 40, 300-306.

11 P. Goldstraw, D. Ball, J. R. Jett, T. Le Chevalier, E. Lim, A. G. Nicholson and F. A. Shepherd, Lancet, 2011, 378, 1727-1740.

12 F. Sen Zhang, J. Keats, Y. Ning, S. D. Wardwell, L. Moran, Q. K. Mohemmad, E. Ye, R. Anjum, Y. Wang and X. Zhu, AACR poster session, 2010.

13 R. M. Squillace, R. Anjum, D. Miller, S. Vodala, L. Moran, F. Wang, T. Clackson, A. P. Garner and V. M. Rivera, Cancer Res., 2013, 73, 5655.

14 D. C. Evans, A. P. Watt, D. A. Nicoll-Griffith and T. A. Baillie, Chem. Res. Toxicol., 2004, 17, 3-16.

15 A. S. Kalgutkar, D. K. Dalvie, J. P. O'Donnell, T. J. Taylor and D. C. Sahakian, Curr. Drug Metab., 2002, 3, 379-424.
16 U. A. Boelsterli, Curr. Drug Metab., 2002, 3, 439-450.

17 S. R. Knowles, J. Uetrecht and N. H. Shear, Lancet, 2000, 356, 1587-1591.

18 C. Ju and J. Uetrecht, Curr. Drug Metab., 2002, 3, 367-377.

19 D. J. Naisbitt, D. P. Williams, M. Pirmohamed, N. R. Kitteringham and B. K. Park, Curr. Opin. Allergy Clin. Immunol., 2001, 1, 317-325.

20 W. G. Chen, C. Zhang, M. J. Avery and H. G. Fouda, in Biological Reactive Intermediates VI, Springer, 2001, pp. 521-524.

21 S. Ma and M. Zhu, Chem.-Biol. Interact., 2009, 179, 25-37.

22 A. F. Stepan, D. P. Walker, J. Bauman, D. A. Price, T. A. Baillie, A. S. Kalgutkar and M. D. Aleo, Chem. Res. Toxicol., 2011, 24, 1345-1410.

23 S. Ma, S. K. Chowdhury and K. B. Alton, Curr. Drug Metab., 2006, 7, 503-523.

24 L. P. Masic, Curr. Drug Metab., 2011, 12, 35-50.

25 Z. Zhang, Q. Chen, Y. Li, G. A. Doss, B. J. Dean, J. S. Ngui, M. Silva Elipe, S. Kim, J. Y. Wu, F. Dininno, M. L. Hammond, R. A. Stearns, D. C. Evans, T. A. Baillie and W. Tang, Chem. Res. Toxicol., 2005, 18, 675-685.

26 B. K. Park, A. Boobis, S. Clarke, C. E. Goldring, D. Jones, J. G. Kenna, C. Lambert, H. G. Laverty, D. J. Naisbitt and S. Nelson, Nat. Rev. Drug Discovery, 2011, 10, 292-306.

27 A. A. Kadi, S. M. Amer, H. W. Darwish and M. W. Attwa, RSC Adv., 2017, 7, 36279-36287.

28 S. Ma and R. Subramanian, J. Mass Spectrom., 2006, 41, 1121-1139.

29 A. Tolonen, M. Turpeinen and O. Pelkonen, Drug discovery today, 2009, 14, 120-133.

30 D. R. Camidge, L. Bazhenova, R. Salgia, C. J. Langer, K. A. Gold, R. Rosell, A. T. Shaw, G. J. Weiss, N. I. Narasimhan, D. J. Dorer, V. M. Rivera, T. P. Clackson, M. G. Conlan, D. Kerstein, F. G. Haluska and S. N. Gettinger, J. Clin. Oncol., 2015, 33, 8062.

31 US FDA, https://www.accessdata.fda.gov/drugsatfda_docs/ nda/2017/208772orig1s000toc.cfm, Multi-Discipline Review/Summary, Clinical, Non-Clinical (PDF file), accessed December 2017.

32 R. von Jagow, H. Kampffmeyer and M. Kinese, NaunynSchmiedebergs Arch. Exp. Pathol. Pharmakol., 1965, 251, 7387.

33 J. Wen, S. Bao, Y. Cai, B. Zhang, R. Wang, C. Wang and G. Hu, J. Chromatogr. B: Anal. Technol. Biomed. Life Sci., 2017, 1068-1069, 84-89.

34 T. Rousu and A. Tolonen, Rapid Commun. Mass Spectrom., 2011, 25, 1382-1390.

35 A. A. Kadi, H. W. Darwish, M. W. Attwa and S. M. Amer, $R S C$ Adv., 2016, 6, 72575-72585.

36 S. Amer, A. A. Kadi, H. W. Darwish and M. W. Attwa, $R S C$ Adv., 2017, 7, 4479-4491. 